\title{
A comparative study of health-promoting lifestyles in agricultural and non-agricultural workers in Japan
}

\author{
Shi-chen Zhang $\cdot$ Chang-nian Wei $\cdot$ \\ Kumiko Fukumoto $\cdot$ Koichi Harada • \\ Kimiyo Ueda $\cdot$ Keiko Minamoto $\cdot$ Atsushi Ueda
}

Received: 8 April 2010/Accepted: 10 July 2010/Published online: 13 August 2010

(C) The Japanese Society for Hygiene 2010

\begin{abstract}
Objectives To clarify the difference in health-promoting lifestyles between agricultural and non-agricultural workers in Japan, a cross-sectional study was conducted on 627 residents living in a town with a mixed rural-urban population.

Methods The subjects were divided into 8 groups by job (agricultural and non-agricultural), age (young and old), and gender (male and female). To evaluate the subjects' lifestyles, the Health Promoting Lifestyle Profile II (HPLP-II) was applied. The Bartlett test and the Kendall rank test were performed for statistical analysis.

Results There was no significant difference in the overall score of the HPLP-II between the two job groups. However, for the HPLP-II subscales, a significantly higher score for "spiritual growth" and a significantly lower score for "physical activity" were seen in the agricultural group than in the non-agricultural group. In general, the old and female groups showed higher scores than the corresponding groups, regardless of job type.

Conclusions It was determined that the major countermeasures to maintain a healthy lifestyle in agricultural
\end{abstract}

S. Zhang $(\bowtie) \cdot$ C. Wei $\cdot$ K. Minamoto $\cdot$ A. Ueda Department of Preventive and Environmental Medicine, Graduate School of Medical Sciences, Kumamoto University, 1-1-1 Honjo, Kumamoto, Kumamoto 860-8556, Japan e-mail: melody0724978@yahoo.co.jp

K. Fukumoto

Kyushu University of Nursing and Social Welfare,

Kumamoto, Japan

K. Harada $\cdot$ K. Ueda

Graduate School of Medical Sciences,

Kumamoto University, Kumamoto, Japan workers should be associated with how to introduce daily activities that maintain and enhance "spiritual growth" and improve "physical activity".

Keywords Lifestyle $\cdot$ Health promotion - Quality of life · Health Promoting Lifestyle Profile-II · Agriculture

\section{Introduction}

The Scientific Committee on Rural Health in the International Commission on Occupational Health stated in the action plan for 2006-2009 that agriculture was still one of the most dangerous and unsafe of all human activities [1]. In Japan, among industrial employees who received a legal periodical medical examination, a higher rate of abnormal findings was seen in those working in the primary industrial sector [2]. Yamane reported that a relative disadvantage in the overall supply of primary health care and a severe erosion of hospital-based and emergency medical services were urgent problems in rural communities in the first decade of the twenty-first century [3]. Ueda reported that, in addition to the issues of health and safety, the agricultural sector has been facing severe socioeconomic problems, such as rapid reductions in the size of the workforce and the output of agricultural products, an increasing proportion of women and elderly workers, and changes in agricultural management [4]. These situations may counteract attempts to maintain a healthy lifestyle in agricultural workers, resulting in a fall in their quality of life (QOL).

As described in the Declaration of Health Promotion proposed by the WHO [5], the significant association of lifestyle with QOL is widely understood. In the Healthy Japan 21 proposed by the Japanese Ministry of Health, 
Labor and Welfare [6], in which the concept and techniques of health promotion were to be introduced, the importance of improving lifestyle and maintaining a healthy lifestyle was emphasized.

To measure and evaluate lifestyle or daily activity, the Health-Promoting Lifestyle Profile (HPLP) is now widely used [7]. The HPLP-II is an upgraded version of the HPLP, which has been used extensively in health promotion research [8] and has been reported to have sufficient validity and reliability by various studies that explored the determinants and actual state of a health-promoting lifestyle [9-12]. In Japan, the Japanese version of the HPLP-II was developed by Wei et al. [13], and has been used by many researchers [14].

Several studies have found certain sociodemographic variables related to a health-promoting lifestyle. In terms of age, some studies reported that older age groups tended to have healthier lifestyles than younger age groups $[11,15$, 16]. In terms of gender, many studies suggested that the frequency and intensity of performance of healthy behaviors were better in females than in males [17-21]. There have also been some studies on the importance of job type, which showed some differences in health behaviors among people with different occupations for individuals with various ethnic origins [22-28].

As mentioned above, there are various negative factors in the daily life of agricultural workers that greatly affect their lifestyles. The situation indicates that it is necessary and important to clarify these precisely and to improve the lifestyles of agricultural workers. However, to date, there have been few studies on the lifestyles of agricultural workers undertaken via a comparison with those of workers in other industrial sectors.

As such, we conducted the present research to clarify the actual state of health-promoting lifestyles in agricultural workers by comparison with those of non-agricultural workers living in the same district. This research may contribute to the understanding of occupational and regional health personnel, especially those in mixed ruralurban societies, to clarify the actual state of daily activities of agricultural and non-agricultural workers and to develop programs to improve them.

\section{Methods}

Town A conducted an action plan for creating a healthy town along with the Healthy Japan 21 [6] in 2005 and we participated in that project. As the first part of the project, the present questionnaire survey was carried out to clarify the actual state of subjective health, lifestyle, health behavior, and lifestyle-related factors among the residents of Town A.
Structure of the questionnaire

The Japanese version of the [13] was used to evaluate the actual state of each resident's lifestyle. This version, which is the same as the original English-language HPLP-II [8], contains six subscales (a total of 52 items); namely, health responsibility (HR), spiritual growth (SG), physical activity (PA), interpersonal relations (IR), nutrition (N), and stress management (SM). The overall score of the HPLP-II as a comprehensive evaluation of a person's lifestyle was calculated from the mean score of the 52 items. Each respondent was asked to rate each item on a Likert response scale as follows: 1 never, 2 sometimes, 3 often, 4 routinely. The scoring of each item was calculated by the procedure proposed in the original article [8], with a higher score indicating a better health-promoting lifestyle. In the preceding study, the values of Cronbach's $\alpha$ in the overall HPLP-II and six subscales had been reported to be 0.91 and $0.70-0.87$, respectively [13].

The information on health and lifestyle-related factors was obtained, on the basis of the framework of the PRECEDE-PROCEED model [29], by group work organized with residents of Town A and our colleagues, who participated in the project. The final questionnaire was composed of a fact sheet, the HPLP-II, and additional factors related to health and daily behavior. In the present study, only the data for HPLP-II, some demographic data (job, age, and gender) and data on subjective health were utilized. The results of more detailed analysis using all of the data in the questionnaire will be described in another article.

\section{Study population and data collection}

Town A was a mixed rural-urban society with $19.0 \%$ of the population working in agriculture (the national average was $4.4 \%$ ) and the main agricultural activity was greenhouse cultivation of vegetables [30]. A total of 3141 residents (18-64 years) were selected randomly from the list of registered residents in Town A, to whom the questionnaire was posted with a form concerning informed consent; $1270(40.4 \%)$ questionnaires were returned for this study, and after uncompleted questionnaires were discarded 1176 remained. In the present study, the sample respondents consisted of the following occupational groups: (1) primary industry workers, almost all of whom were agricultural workers in Town A; (2) secondary industry workers, generally engaging in manufacturing, a fairly small population in Town A; (3) tertiary industry workers, including office workers, public employees, and health service workers, who had similar employment characteristics, such as a regular salary, a limited working life (retire at around 60), and regular work hours. So we considered these people as one group (as regular employees); (4) informal sectors, 
such as irregular employees, the self-employed, and the unemployed; (5) students; and (6) housewives (see Table 1). Among these groups we chose groups (1) and (3) for the present research samples, because groups (1) and (3) had a homogeneous working mode, as mentioned above, differing from the other groups (2), (4), (5), and (6). Of course, groups (2), (4), (5), and (6) are important working populations in a community but we could not gather enough samples with clear characteristics for analysis for the present comparative study in Town A. And as for the housewife group (6), the term "housewife" is not defined clearly in Japan and housewives are not considered to have a homogeneous lifestyle; also there are rare cases of housewives participating in agricultural households. From this viewpoint, we did not consider this group for our research sample, and our subjects were groups (1) and (3).

Consequently, a total of 627 questionnaires were selected and the respondents were divided into two occupational groups: 130 agricultural workers $(20.7 \%$ of the present sample), who engaged in agriculture for 150 days in a year; and 497 non-agricultural workers (79.3\%), including office workers, public employees, and health service workers. There were 65 males $(50 \%$ of the agricultural group) and 65 females $(50.0 \%)$ in the agricultural group; in contrast, there were 292 males $(58.7 \%)$ and 205 females $(41.3 \%)$ in the non-agricultural group, showing a significant difference in sex ratios between the two job groups $(p=0.045)$. In terms of age, the average for the males in the agricultural group was $50.0 \pm 11.4$ years, and that of females was $49.4 \pm 10.7$ years. The average age of males in the non-agricultural group was $45.0 \pm 11.3$ years and that of females was $40.6 \pm 11.3$ years, showing a significant difference in mean age by sex in both of the job groups $(p<0.0001)$.

\section{Statistical analysis}

As mentioned above, the proportions of individuals with regard to age and gender were different in the two job groups, reflecting the present demographic situation of Town A and also that in Japan; it would be difficult to compare these two job groups by a simple-distributiondependent statistical method.

In the present analysis, the age distribution of the present samples was shown to be $47-48$ years in the 50th percentile, and the overall HPLP-II score showed a significant difference when compared between the age groups of $18-49$ and $50-64$ years $(p<0.0001)$. In the report of Breslow et al. [31] the mean health status score of the people in the community in their follow-up samples was indicated to be in those aged 50-55 years. Accordingly, we divided our samples into two age groups with the cutoff at 50 years.

Finally, the subjects were divided into 8 groups according to their job (agricultural and non-agricultural), age (young 18-49 years and old 50-64 years), and gender (male and female) (Table 2).

Firstly, the Bartlett test [32] of one-way analysis of variance was used to clarify the differences in overall scores and the scores for the subscales of the HPLP-II between the 8 groups. In addition, according to each overall score and the scores for the 6 subscales of the HPLP-II, each group was ranked and assigned a ranking position from first to eighth.

Next, in order to clarify the difference between the agricultural and non-agricultural groups, as well as the differences between age (young and old) and gender (male and female) groups, in terms of overall scores and scores for subscales of the HPLP-II, we applied the Kendall rankorder correlation coefficient (Kendall's $\tau$ ) [33] as a nonparametric method. Briefly, the scores of the eight groups, shown in Fig. 1, were ranked from high to low; namely, from that ranked first to that ranked eighth. In terms of the job group, each of the 4 agricultural groups (young/old and male/female) was given the same rank of first (each assigned the number of 2.5 as the average rank value of each group) and each of the 4 non-agricultural groups was given the rank of fifth (the number being 6.5). The same procedures were performed for gender groups [males given the rank of first (the number being 2.5) versus females given the rank of fifth (6.5)] and age [the young given the rank of first (2.5) versus the old given the rank of fifth (6.5)]. In this analysis, a positive value of Kendall's $\tau$ indicated that the agricultural, male, and young groups were assumed to have a better HPLP-II score than the opposite groups, whereas a negative value indicated the converse. In both analyses (i.e., the Bartlett test and Kendall's $\tau$ ), the difference was considered to be statistically significant when $p<0.05$.

NAP version 4.0 (NAP, Mac (c) $1994 \sim$ S.Aoki, Japan) and SPSS package version 11 (SPSS, Chicago, IL, USA) were used for statistical analyses.

\section{Ethical considerations}

In the present study, implemented as a part of community health services, all selected subjects were informed of the purpose of the study and were assured of confidentiality upon receiving the questionnaire. Consent to participate in the study was confirmed for those who completed and returned the questionnaire. Study data were processed in a restricted place, using a personal unidentifiable code for each subject. 


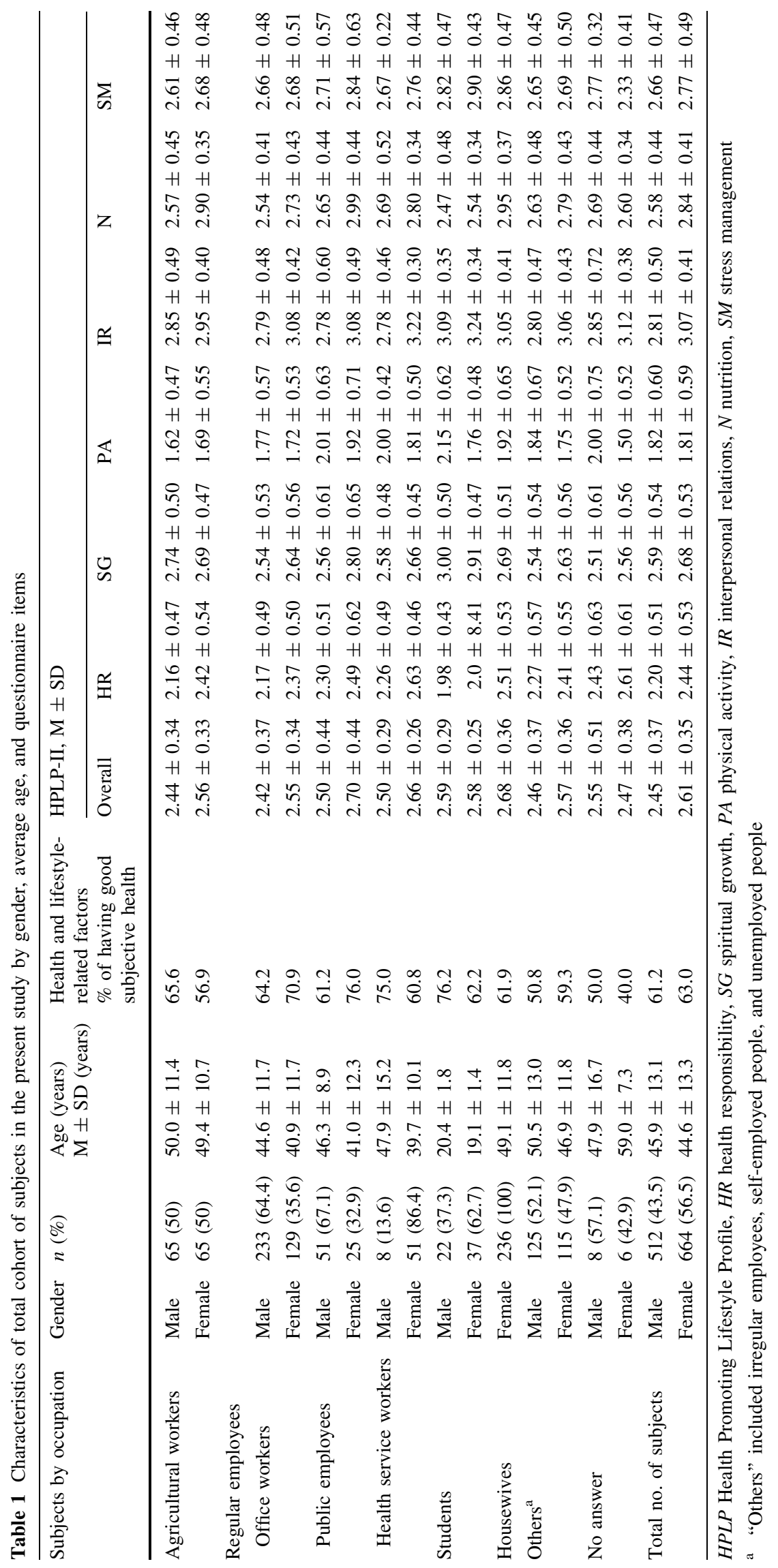




\section{Results}

Reliability of the questionnaire

Cronbach's $\alpha$ coefficient for the overall score and subscales of the HPLP-II was shown to have a high value, the same as that in previous research by Wei et al. [13], with an $\alpha$ coefficient of 0.92 overall and $0.68-0.83$ for the subscales.

Characteristics of the subjects

Some characteristics of the total number of subjects in the present study, such as age, the percentage of those having good subjective health, and the scores for the domains of the HPLP-II stratified by sex and occupational status are summarized in Table 1.

In the present study, we focused on agricultural and nonagricultural workers by dividing the subjects into 8 groups, as mentioned above. The mean age of each group is shown in Table 2, showing that there was no statistically significant difference in the mean age between the 4 young groups, or between the 4 old groups.

Table 2 Number of subjects and mean age in each group

\begin{tabular}{|c|c|c|c|c|c|}
\hline \multirow[t]{2}{*}{ Group } & \multicolumn{2}{|c|}{$\begin{array}{l}\text { Agricultural } \\
(n=130)\end{array}$} & \multicolumn{2}{|c|}{$\begin{array}{l}\text { Non-agricultural } \\
(n=497)\end{array}$} & \multirow[t]{2}{*}{$p$} \\
\hline & $n$ & Mean age (years) & $n$ & Mean age (years) & \\
\hline \multicolumn{6}{|l|}{ Young } \\
\hline Male & 23 & $37.5 \pm 9.4$ & 173 & $37.6 \pm 8.5$ & \multirow[t]{2}{*}{$0.633^{\mathrm{a}}$} \\
\hline Female & 30 & $39.8 \pm 7.6$ & 152 & $35.4 \pm 8.0$ & \\
\hline \multicolumn{6}{|l|}{ Old } \\
\hline Male & 42 & $56.9 \pm 4.3$ & 119 & $55.7 \pm 3.2$ & \multirow[t]{2}{*}{$0.317^{\mathrm{b}}$} \\
\hline Female & 35 & $57.5 \pm 3.9$ & 53 & $55.5 \pm 3.8$ & \\
\hline
\end{tabular}

${ }^{a} p$ values of the difference in mean age between the 4 young groups by the Bartlett test

${ }^{\mathrm{b}} p$ values of the difference in mean age between the 4 old groups by the Bartlett test

Fig. 1 Mean overall Health Promoting Lifestyle Profile (HPLP)-II scores (a) and mean scores for the HPLP-II subscales (b-g), as well as rank orders (a-g) for agricultural $(n=130)$ and non-agricultural groups $(n=497)$. Data are means \pm SD. Statistical analysis was performed by the Bartlett test of one-way analysis of variance. Significant differences between corresponding groups are indicated as follows: $* p<0.05, * * p<0.01, * * * p<0.001$. Numbers in circles (1)-(8) indicate the rank order of each score in each group. Symbols for the agricultural group are as follows: open squares young-male, open triangles old-male, open circles young-female, open diamonds oldfemale. Symbols for the non-agricultural group are as follows: filled squares young-male, filled triangles old-male, filled circles youngfemale, filled diamonds old-female
A

1. Overall
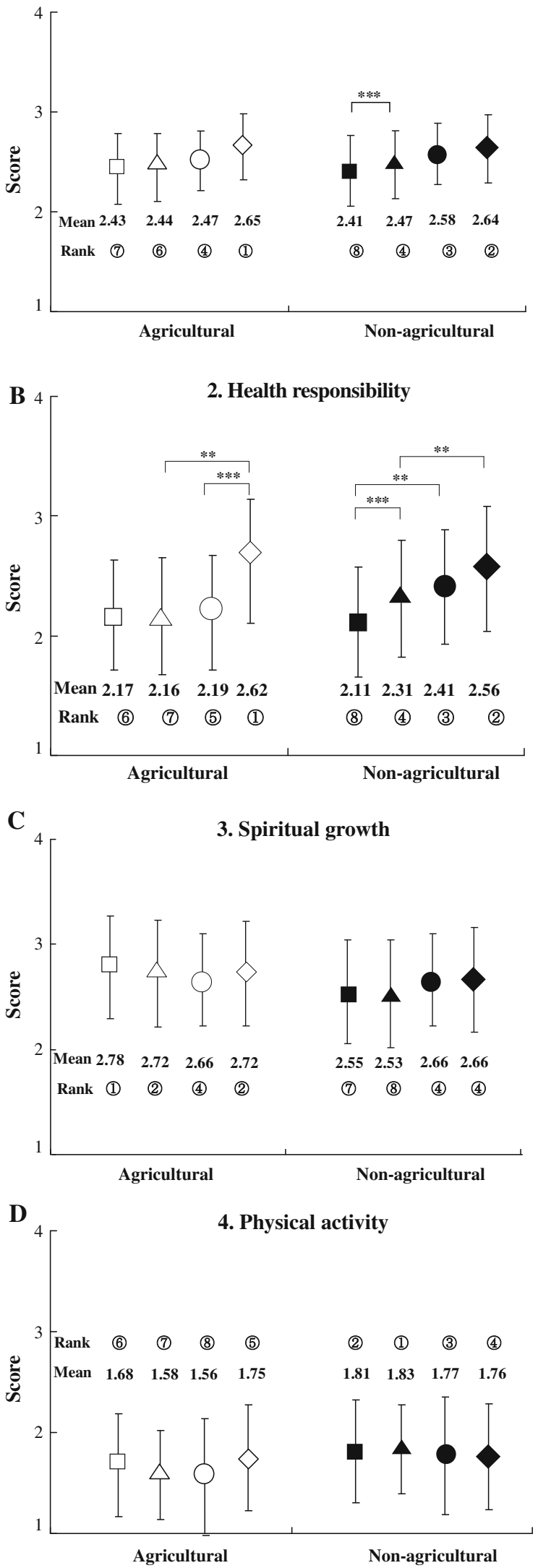
A healthy subject was defined as one who answered "yes" to the question concerning subjective health of "I think I am healthy".

In the present subjects a significant correlation was seen in the score for subjective health (0-2) to overall HPLP-II ( $r=0.146 p<0.0001$ ), and also a significant correlation was seen to each subscale of the HPLP-II $(r=0.23$, $p<0.001$ for SG, $r=0.08, p<0.05$ for $\mathrm{PA}, r=0.12$, $p<0.01$ for IR, $r=0.07, p<0.05$ for $\mathrm{N}, r=0.18, p<$ 0.001 for $\mathrm{SM})$ except for $\mathrm{HR}(r=-0.04$, not significant).
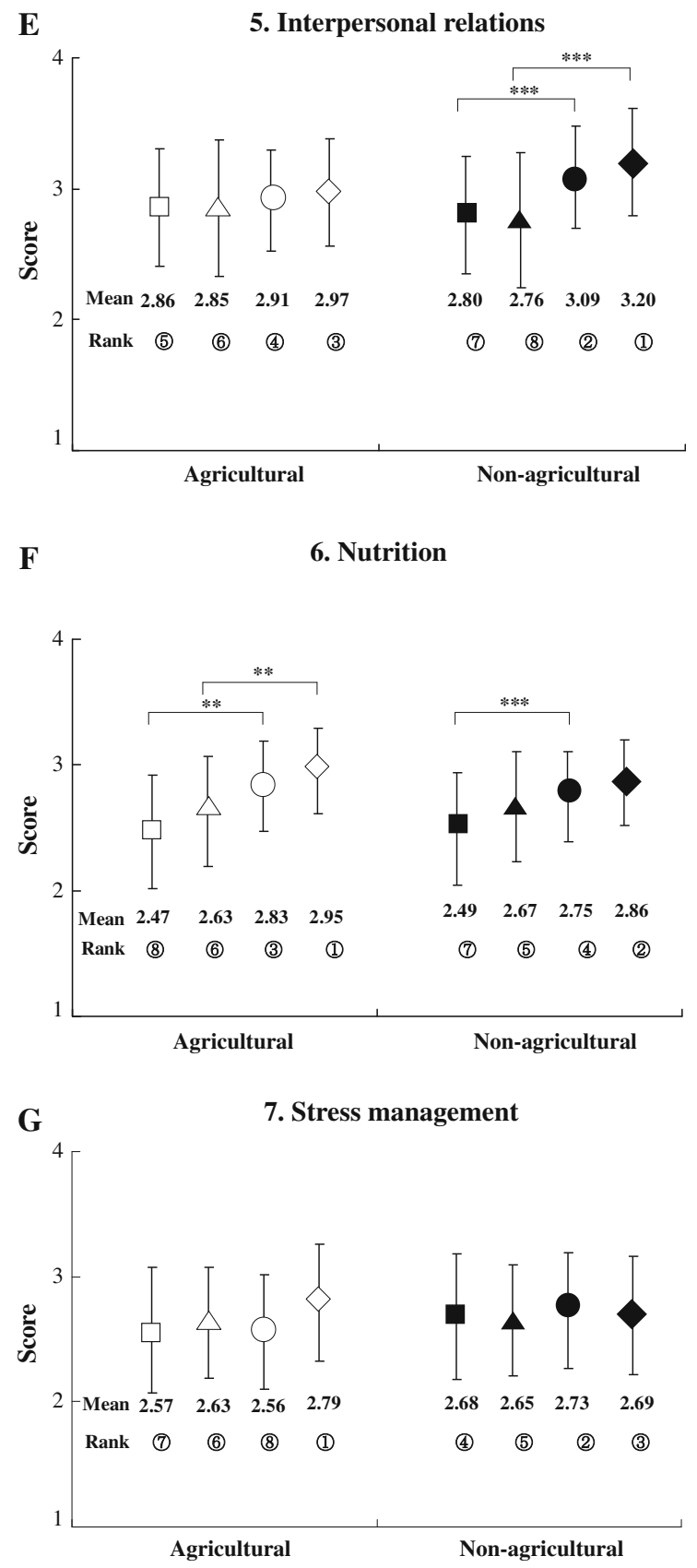

Fig. 1 continued
The positive rates for good subjective health of the subjects in each group are summarized in Table 3. A significant difference was observed between the 8 groups ( $p<0.0001$ by the $\chi^{2}$ test) and the young-female-agricultural group showed the lowest value and the youngfemale-non-agricultural group showed the highest value. In the female groups, a lower rate was generally seen in the agricultural group than in the non-agricultural group; however, no significant difference was found for agricultural versus non-agricultural in the young-female group $(p=0.068)$, or in the entire female group $(p=0.052)$.

Differences in overall scores and scores for the six subscales of the HPLP-II between the 8 groups by the Bartlett test

The overall scores and scores for the six subscales of the HPLP-II in the agricultural and non-agricultural groups are summarized in Fig. 1a-g. The rank of the score of each group is indicated below the mean value of each group in the figure.

For the overall HPLP-II score, as shown in Fig. 1a, the female group and the old group showed, in general, higher scores than the male and the young group in both occupational groups; however, a significantly higher score was seen only in the old male non-agricultural group compared with the young male non-agricultural group ( $p<0.001)$.

For the subscale HR (Fig. 1b), the female non-agricultural group showed a significantly higher score than the male non-agricultural group [both in the young $(p<0.01)$ and old groups $(p<0.01)]$. In addition, old male workers showed significantly higher scores than young males in the non-agricultural group $(p<0.001)$. The old female agricultural group showed significantly higher scores than the old male agricultural group $(p<0.01)$ and the young female agricultural group $(p<0.001)$.

For the subscale SG (Fig. 1c), the agricultural group showed, in general, a higher score than the non-agricultural group; however, no significant difference was found.

For the subscale PA (Fig. 1d), the agricultural groups showed, in general, lower scores than the corresponding

Table 3 Rates of subjects having good subjective health in agricultural and non-agricultural groups

\begin{tabular}{llll}
\hline Group & $\begin{array}{l}\text { Agricultural } \\
(n=130) \\
n(\%)\end{array}$ & $\begin{array}{l}\text { Non-agricultural } \\
(n=497) \\
n(\%)\end{array}$ & $p^{\mathrm{a}}$ \\
\hline Young-male & $15(65.2)$ & $110(64.3)$ & 0.565 \\
Young-female & $16(53.3)$ & $105(69.5)$ & 0.068 \\
Old-male & $27(65.9)$ & $73(63.5)$ & 0.471 \\
Old-female & $21(60.0)$ & $35(67.3)$ & 0.318 \\
\hline
\end{tabular}

a The $\chi^{2}$ test was performed for the comparison of agricultural versus non-agricultural groups in each age-gender group 
non-agricultural groups; however no significant difference was found.

For the subscale IR (Fig. 1e), significant differences were seen for the female non-agricultural group compared with the male non-agricultural group [both in the young $(p<0.001)$ and the old $(p<0.001)]$.

For the subscale N (Fig. 1f), a significantly higher score was seen in the female agricultural group than in the male agricultural group [both in the young $(p<0.01)$ and the old $(p<0.01)]$. Furthermore, in the non-agricultural group, a significantly higher score was seen in the old female group than in the young female group $(p<0.001)$.

For the subscale SM (Fig. 1g), no significant difference was found between the 8 groups.

Comparisons of the HPLP-II overall scores and scores for the HPLP-II subscales between agricultural and non-agricultural groups, young and old groups, and male and female groups by Kendall rank-order correlation coefficient

The results of the Kendall rank-order test for job (agricultural and non-agricultural), age (young and old), and gender (male and female) are summarized in Table 4. A significantly higher rank value was found for $S G$ in the agricultural group than in the non-agricultural group ( $\tau=0.714, p=0.037$ ). PA showed a significantly lower rank value in the agricultural group than in the non-agricultural group $(\tau=-0.756, p=0.021)$. However, no significant difference in rank value between the two job groups was found for the overall score or for the scores for the other subscales.

Table 4 The $\tau$ values by the Kendall rank test for the overall HPLP-II score and the six subscales of the HPLP-II by job, age, and gender groups

\begin{tabular}{|c|c|c|c|c|c|c|}
\hline \multirow[t]{2}{*}{ Domain } & \multicolumn{2}{|l|}{$\mathrm{Job}^{\mathrm{b}}$} & \multicolumn{2}{|l|}{$\mathrm{Age}^{\mathrm{c}}$} & \multicolumn{2}{|l|}{ Gender $^{\mathrm{d}}$} \\
\hline & $\tau^{\mathrm{a}}$ & $p$ & $\tau^{\mathrm{a}}$ & $p$ & $\tau^{\mathrm{a}}$ & $p$ \\
\hline Overall & -0.048 & 0.885 & -0.722 & 0.029 & -0.722 & 0.029 \\
\hline $\begin{array}{l}\text { Health } \\
\text { responsibility }\end{array}$ & -0.094 & 0.773 & -0.378 & 0.248 & -0.661 & 0.043 \\
\hline Spiritual growth & 0.714 & 0.037 & 0.000 & 1.00 & -0.051 & 0.882 \\
\hline Physical activity & -0.756 & 0.021 & -0.094 & 0.773 & 0.189 & 0.564 \\
\hline $\begin{array}{l}\text { Interpersonal } \\
\text { relations }\end{array}$ & 0.000 & 1.00 & 0.000 & 1.00 & -0.756 & 0.021 \\
\hline Nutrition & 0.000 & 1.00 & -0.378 & 0.248 & -0.756 & 0.021 \\
\hline Stress management & -0.378 & 0.248 & -0.283 & 0.386 & -0.378 & 0.248 \\
\hline
\end{tabular}

${ }^{\text {a }}$ Positive $\tau$ values indicate that agricultural, male, and young groups appeared to have better scores for the HPLP-II domains than the opposite groups, whereas negative values indicate the converse

b Job: Agricultural versus non-agricultural

c Age: Young versus old

${ }^{\mathrm{d}}$ Gender: male versus female
In terms of age, the young group showed significantly lower values than the old group for the overall score ( $\tau=-0.722, p=0.029$ ). There was no significant difference in rank value for the other subscales.

In terms of gender, the male group showed significantly lower values than the female group for the overall score ( $\tau=-0.722, p=0.029)$, and for HR $(\tau=-0.661, p=$ $0.043)$, IR $(\tau=-0.756, p=0.021)$, and $\mathrm{N}(\tau=-0.756$, $p=0.021)$.

\section{Discussion}

The present study was conducted to clarify the actual state of the lifestyle in agricultural workers, for whom some critical factors, including not only physiological and mental workload but also various kinds of socioeconomic and demographic situations, have generally been recognized as affecting their lifestyle. We selected subjects and controls by random sampling from a governmental list of registered residents in Town A.

Town A is a typical Japanese rural-urban mixed society, in which fulltime farmers constitute $19.0 \%$ of the population, which provides an appropriate model and sample for comparing the actual lifestyle situation between agricultural and non-agricultural workers.

As summarized in Table 2, the age and gender proportions were different between the two job groups in our study (agricultural and non-agricultural workers), reflecting the present demographic situation in Town A. Similar phenomena are found throughout Japan. It was difficult to compare these two job groups by a simple-distributiondependent statistical method. We devised a specific statistical procedure as follows.

As a first step, after dividing the subjects into 8 groups of two opposite groups of job, age, and sex, we performed the Bartlett test [32] of one-way analysis of variance to clarify the differences in the HPLP-II overall scores and the scores for the six subscales of the HPLP-II between the 8 groups. As a second step, after ranking the 8 groups from first to eighth according to each mean score, we applied the Kendall rank-order correlation coefficient (Kendall's $\tau$ ) [33] as a nonparametric method to clarify the difference in the HPLP-II scores between the agricultural and nonagricultural groups, and also between the different age (young and old) and gender (male and female) groups. The Kendall $\tau$ rank correlation coefficient, developed by Kendall in 1938 , is commonly used to measure the degree of correspondence between two rankings and to assess the significance of this correspondence. Thus we applied this method to investigate how to accumulate the rank of the scores in the specific group by giving the rank of first to the 4 agricultural groups and fifth to the 4 non-agricultural 
groups. Although the application of the Kendall rank test to the present analysis may not always fit directly with the statistical concept of the Kendall rank test, we think that the present statistical procedure may have been the proper choice as a new statistical method for this study.

As a whole, this study is the first comparative study to have evaluated the actual lifestyle condition in agricultural workers living in a district with a rural-urban mixed society. The results may contribute to helping regional public healthcare professionals to develop health service plans, by considering the individual and occupational differences of residents.

Firstly, by the calculation of a single correlation coefficient, we confirmed that the overall HPLP-II score and the scores for the 6 HPLP-II subscales were significantly related to the study subjects' subjective health

Secondly we clarified that, especially from the results of the Kendall rank test, gender and age appeared to greatly influence the lifestyles of both agricultural and non-agricultural workers, a finding which is consistent with previous reports on various working populations $[11,16,18-21$, 24-27, 34-36]. For example, in terms of the association of age with lifestyle, it was reported that the nutritional condition was significantly better for old workers than young workers. In addition, in blue-collar workers, the old age group performed less exercise but showed more health responsibility and practiced healthier nutrition. In terms of gender, it was reported that females showed more healthprotective behaviors. Bagwell and Bush [11] noted that females scored significantly higher than males in health responsibility and interpersonal relations. Furthermore, many studies have suggested that the frequency and intensity of the performance of good health behavior varied between males and females. In the present study, it was a noteworthy result that a tendency was shown toward higher overall HPLP-II scores and higher scores for the six HPLP-II subscales only in the female-old-agricultural group compared with the female-young-agricultural group; nevertheless, higher ranks for the scores were seen in the female-young-agricultural group than in the two male groups. This tendency might reflect a critical situation at present in the female-young-agricultural workers and indicates that further investigation should be conducted to clarify a critical situation, from social and work physiological aspects, in e young female agricultural workers.

Finally we clarified that there was no significant difference in the overall HPLP-II score between the agricultural group and the non-agricultural group in the present study. However, as to the HPLP-II subscales, a significantly higher SG score and a significantly lower PA score were seen in the agricultural group compared with the nonagricultural group.
As Wei et al. reported [13], the SG subscale consists of 9 items representing happy and positive feelings and strong intentions for the future and the PA subscale consists of 8 items that reflect a persevering attitude and the practice of exercise. The items in both of these subscales are recognized as advantageous factors for achieving a high QOL, by reducing stress and by enhancing physical activities, respectively.

Ueda [4] reported that SG was a natural attribute of agricultural workers because agricultural work and life are based on a creative element that is latent in primary industry. From this viewpoint, it is of great importance for public health professionals to educate agricultural workers that they possess an advantage with regard to elements of lifestyle through their agricultural work and life; such education could thus increase the interest of community residents in agriculture, by promoting an understanding of the importance and benefits of agricultural work.

PA is considered to be one of the most important and common activities for improving residents' lifestyle. However, it should be noted that because the items reflecting exercise in the questionnaires used in the present study were associated with jogging, swimming, or other formal sports (which are the common methods of exercising among non-agricultural workers) whereas for agricultural workers, exercise usually includes walking, doing housework, and carrying out job-related activities, their scores may have been underestimated. Further investigation is necessary to clarify this point.

We note that agricultural workers showed and maintained higher SG scores, a finding which is considered to be probably due to their living environment. So, it is more applicable and effective to improve the lifestyle of agricultural workers by further improving SG, which is relatively easy to achieve, rather than by attempting to improve the items with lower scores, such as PA, which is relatively difficult to improve at present.

We concluded that introducing activities for maintaining and enhancing the condition of SG, and improving the condition of PA would be effective countermeasures for maintaining a desirable lifestyle in agricultural workers in a rural-urban mixed society.

It is also necessary and important for public health professionals to introduce knowledge and techniques of exercise to agricultural workers and to make arrangements for places for training and equipment for the purpose of exercise establishment and the development of better PA.

Besides factors such as income, education, and marital status, job, age, and gender may also be very important factors related to health-promoting behaviors [16, 34, 37]. Further investigations regarding these factors for regulating individual health-promoting behaviors are warranted. 


\section{Conclusions}

We conducted a cross-sectional survey to clarify the actual condition of a health-promoting lifestyle in agricultural workers in comparison with that of non-agricultural workers living in the same town. The findings were as follows:

(1) There was no significant difference in the overall HPLP-II score between the agricultural group and the non-agricultural group.

(2) For the HPLP-II subscales, a significantly higher SG score and a significantly lower PA score were seen in the agricultural group compared with the non-agricultural group.

(3) The female group tended to show a significantly higher overall HPLP-II score than the male group.

(4) The old group had higher overall scores and higher scores for HR, IR, and $\mathrm{N}$ than the young group.

(5) Accordingly, the results suggested that introducing daily activities to maintain and enhance SG and improve PA would be effective measures to maintain a desirable lifestyle for agricultural workers.

Acknowledgments The authors thank the staff of the Health and Welfare section of Town A for their cooperation on-site during the process of data acquisition. The present study was undertaken as part of the national model project, Health-Up Model Project, of the National Health Insurance, the Ministry of Health, Welfare and Labor.

\section{References}

1. Scientific Committee of on Rural Health. Agriculture, pesticides and organic dusts work plan 2006-2009. ICOH; 2007.

2. Journal of Health and Welfare Statistics. Health \& Welfare Statistics Association. 2009;56(9):314

3. Yamane Y. Health promoting rural community in Japan: a path to the future. JRM. 2006;2:47-77.

4. Ueda A. Stress and stress coping in Japanese agricultural workers. Agric Med Rural Health. 2000;48(6):830-44. (in Japanese with English abstract).

5. WHO. Ottawa charter for health promotion. Health Promot Int. 1, iii-v; 1986.

6. Sakurai H. Healthy Japan 21. JMAJ. 2003;46(2):47-9.

7. Walker S, Sechrist K, Pender N. The health-promoting lifestyle profile: development and psychometric characteristics. Nurs Res. 1987;36(2):76-81.

8. Walker S, Sechrist K, Pender N. The Health-Promoting Lifestyle Profile II. Omaha: University of Nebraska Medical Center, College of Nursing; 1995.

9. Walker S, Volkan K, Sechrist K, Pender N. Health-promoting lifestyles of older adults: comparisons with young and middle-aged adults, correlates and patterns. ANS Adv Nurs Sci. 1988;11(1): 76-90.

10. Acton G, Malathum P. Basic need status and health-promoting self-care behavior in adults. West J Nurs Res. 2000;22:796-811.

11. Bagwell MM, Bush HA. Health conception and health promotion in blue collar workers Program planning issues. AAOHN J. $1999 ; 47: 512-8$.
12. Clement M, Bouchard L, Jankowski L, Perreault M. Health promotion behaviors in first year undergraduate nursing students. Can J Nurs Res. 1995;27(4):111-31.

13. Wei CN, Yonemitsu H, Harada K, Miyakita T, Omori S, Miyabayashi T, Ueda A. A Japanese language version of the health-promoting lifestyle profile. Jpn J Hyg. 2000;54:597-606. (in Japanese with English abstract).

14. Nakanishi N, Machiura M. Factors in health promotion behaviors of menopausal women. Matern Health. 2008;48(4):514-21.

15. Resnick B. Health promotion practices of older adults: model testing. Public Health Nurs. 2003;20:2-12.

16. Weitzel MH. A test of the health promotion model with blue collar workers. Nurs Res. 2003;38:99-104.

17. Lee RLT, Yuen Loke AJT. Gender differences in health-promoting lifestyles of African Americans. Public Health Nurs. 2005;22(2):130-7.

18. Harris DM, Gutten S. Health-protective behaviour: an exploratory study. J Health Soc Behav. 1979;20:17-29.

19. Kim SY, Jeon EY, Sohyune RS, Kim KB. Comparison of Healthpromoting behaviors of noninstitutionalized and institutionalized older adults in Korea. J Nurs Scholarsh. 2006;38(1):31-5.

20. Moore S, Kramer F. Women's and men's preferences for cardiac rehabilitation program features. J Cardiopulm Rehabil. 1996;16: $163-8$.

21. Oka R, King A, Young D. Sources of social support as predictors of exercise adherence in women and men ages 50-65 years. Women's Health Res Gender Behav Policy. 1995; 7(2):161-75.

22. Choi Hui WH. The health-promoting lifestyles of undergraduate nurses in Hong Kong. J Prof Nurs. 2002;18(2):101-11.

23. Kerr MJ, Ritchey DA. Health-promoting lifestyles of Englishspeaking and Spanish-speaking Mexican-American migrant farm workers. Public Health Nurs. 1990;7(2):80-7.

24. Robbins L, Pender N, Conn V, Freen M, Neuberger G, Nies MA. Moving toward a healthier future with physical activity research in nursing. J Nurs Scholarsh. 2001;33:315-21.

25. Lusk SL, Kerr MJ, Ronis DL. Health-promoting lifestyles of blue-collar, skilled trade, and white-collar workers. Nurs Res. 1995;44(1):20-4.

26. Pender NJ, Walker SN, Sechrist KR, Stromborg MF. Predicting health-promoting lifestyles in the work-place. Nurs Res. 1990;39:326-32.

27. Duffy M, Rossow R, Hernandez M. Correlates of health-promotion activities in employed Mexican American women. Nurs Res. 1996;45:18-24.

28. Kuster A, Fong C. Further psychometric evaluation of the Spanish language Health Promotion Lifestyle Profile. Nurs Res. 1993;42:266-9.

29. Green LW, Kreuter MW. Health promotion planning-an educational and environmental approach. 3rd ed. Mayfield Publishing, CA; 1999.

30. Ueki Town Kumamoto Pref. Japan. Final Report Survey October 2006. http://www.pref.kumamoto.jp/uploaded/attachment/18593. pdf. Accessed 1 Feb 2009.

31. LISA FB, Breslow L. Health and ways of living. The Alameda County Study. Oxford University Press; 1983.

32. Bartlett MS. Properties of sufficiency and statistical tests. Proc R Stat Soc Ser A. 1937;160:268-82.

33. Kendall M. A new measure of rank correlation. Biometrika. 1938;30(1-2):81-9.

34. Adams MH, Bowden AG, Humphrey DS, McAdams LB. Social support and health promotion lifestyles of rural women. J Rural Nurs Health Care. 2000;1:28-40.

35. Ayse B, Zuhal B, Dilek B. Health promoting behaviors and factors related to lifestyle among Turkish workers and occupa- 
tional health nurses responsibilities in their health promoting activities. Ind Health. 2007;45:151-9.

36. Hulme PA, Walker SN, Effle KJ, Jorgensen L, McGowan MG, Nelson JD, Pratt EN. Health-promoting lifestyles behaviors of Spanish-speaking Hispanic adults. J Transcult Nurs. 2003;14: 244-54.
37. Wallston KA, Wallston BS. Health locus of control scales. In: Lefcourt H, editor. Research with the locus of control construct: assessment methods. vol 1. New York: Academic Press; 1981, p 189-243. 